\title{
Complementary and Alternative Medicine Use in Hospitalized Cancer Patients-Study from Silesia, Poland
}

\author{
Karolina Kasprzycka ${ }^{1}$, Marta Kurzawa ${ }^{1}$, Malgorzata Kucharz ${ }^{1}$, Monika Godawska ${ }^{1}$, Marta Oleksa ${ }^{1}$, \\ Marta Stawowy ${ }^{1}$, Katarzyna Slupinska-Borowka ${ }^{1}$, Wiktoria Sznek ${ }^{1}$ D, Iwona Gisterek ${ }^{1}$ (D), \\ Agnieszka Boratyn-Nowicka ${ }^{2}$, Monika Rucinska ${ }^{3}{ }^{\mathbb{D}}$, Karolina Osowiecka ${ }^{4} *$ and Sergiusz Nawrocki ${ }^{1,3}{ }^{(D)}$
}

check for updates

Citation: Kasprzycka, K.; Kurzawa, M.; Kucharz, M.; Godawska, M.; Oleksa, M.; Stawowy, M.; Slupinska-Borowka, K.; Sznek, W.; Gisterek, I.; Boratyn-Nowicka, A.; et al. Complementary and Alternative Medicine Use in Hospitalized Cancer Patients-Study from Silesia, Poland. Int. J. Environ. Res. Public Health 2022, 19, 1600. https://doi.org/10.3390/ ijerph19031600

Academic Editor: Theresa W. Gillespie

Received: 28 November 2021

Accepted: 28 January 2022

Published: 30 January 2022

Publisher's Note: MDPI stays neutral with regard to jurisdictional claims in published maps and institutional affiliations.

Copyright: (C) 2022 by the authors. Licensee MDPI, Basel, Switzerland. This article is an open access article distributed under the terms and conditions of the Creative Commons Attribution (CC BY) license (https:// creativecommons.org/licenses/by/ $4.0 /)$.
1 Department of Oncology and Radiotherapy and Affiliated Student Science Club, Medical University of Silesia in Katowice, ul. Ceglana 35, 40-514 Katowice, Poland; k.kasprzycka@gazeta.pl (K.K.); mrtkurzawa@gmail.com (M.K.); gkucharz@gmail.com (M.K.); monikagodawska@hotmail.com (M.G.); marta.oleksa@gmail.com (M.O.); martastawowy@gmail.com (M.S.); katarzynajuliaes@gmail.com (K.S.-B.); wsznek@gmail.com (W.S.); igisterek@sum.edu.pl (I.G.); sergiusz.nawrocki@me.com (S.N.)

2 Katowice School of Technology, University of Technology in Katowice, ul. Rolna 43, 40-555 Katowice, Poland; aboratynnowicka@zco-dg.pl

3 Department of Oncology, Collegium Medicum, University of Warmia and Mazury in Olsztyn, 10-228 Olsztyn, Poland; m_rucinska@poczta.onet.pl

4 Department of Psychology and Sociology of Health and Public Health, School of Public Health, University of Warmia and Mazury in Olsztyn, 11-041 Olsztyn, Poland

* Correspondence: karolina.osowiecka@uwm.edu.pl; Tel.: +48-518-711-334

\begin{abstract}
Background: The use of complementary and alternative medicine (CAM) is common amongst cancer patients. The aim of the study was to investigate the use of CAM, beliefs about CAM and the purpose of using it amongst Polish cancer patients. Methods: The study included 864 cancer patients (median 63 years old), who were individually interviewed. The questionnaire was designed specifically for this study. Results: Amongst 732 patients who declared that they heard about CAM, 342 patients $(46.7 \%)$ had used CAM; $91 \%$ of these patients had used it as a complementary therapy and $9 \%$ had used it as an alternative therapy. Patients younger in age, highly educated, professionally active, with longer medical history, and at more advanced cancer stages have, statistically, used CAM more often; $66 \%$ of participants could not state what the health effect of CAM is. Patients received information about CAM from the internet, friends, family and other patients. Only $18 \%$ of patients discussed using CAM with a doctor. Conclusions: CAM was popular amongst Polish cancer patients, especially in younger, educated and professionally active patients with longer cancer history at advanced stage. Patients used CAM as a complementary therapy for strengthening immune system, improving morphological and biochemical test parameters, reducing the side effects of conventional therapy and improving their well-being.
\end{abstract}

Keywords: CAM; complementary medicine; alternative medicine; cancer patients

\section{Introduction}

Some patients use health care approaches that are not typically a part of conventional medical care-complementary and alternative medicine (CAM). CAM includes a wide range of products and medical practices that are not a conventional therapy in Western countries. According to the National Center for Complementary and Integrative Health $(\mathrm{NCCIH})$, complementary medicine is not the same as alternative medicine. If some unconventional approach-action or product - is used together with conventional medicine, it is called complementary. If an unconventional approach is used in the place of standard treatment, it is considered alternative. CAM therapies include herbs, vitamins, minerals, probiotics, nutritional supplements and special diets. Practices such as deep breathing exercises, yoga, tai chi, massage, chiropractic manipulations, magneto-therapy and acupuncture 
also belong to CAM. Psychological CAM include relaxation techniques, qi gong, hypnotherapy, meditation, music/dance therapy and mindfulness-based stress reduction. In Western medicine in recent years, a new approach has appeared-integrative health. In an integrative health approach, CAM is used together with conventional medicine in a coordinated way. Some extra actions, for example lifestyle changes, rehabilitation, psychotherapy and complementary health approaches, can be beneficial during conventional anti-cancer treatment. It is important to provide this kind of care in a coordinated way and to adapt it individually to a given patient's needs [1].

The use of unconventional products and activities is common amongst both healthy and sick populations. Around 36\% of cancer patients in Europe use CAM and the number of patients using unconventional therapies is growing [2]. Cancer patients in particular are willing to explore to alternative therapies. The prevalence of CAM use amongst cancer patients is in the range of 9-88\% and depends on country and cancer type [3]. Meta-analysis of patient data found an increase in CAM use by cancer patients from $25 \%$ in the 1980 s to $32 \%$ in the 1990s and $49 \%$ in the 2000s [3]. Delay or refusal of conventional cancer treatment, due to a belief in alternative medicine, may have a negative impact on survival for cancer patients [4-10]. In Poland, there is still a lack of studies about CAM use among cancer patients. In 2017, there was an intensive discussion in the popular press; the two most widely read Polish magazines were alarmed, reporting that about $75 \%$ of cancer patients used some unconventional therapies [11,12], and that some patients even resigned from conventional, evidence-based treatments. However, it was only a speculation, which was not based on systematic studies or solid data, and was mostly based on interviews with expert oncologists and individual patients. Therefore, at that time, we decided to carry out this study. The aims of this study were to investigate CAM popularity among cancer patients in Poland, explore patients' insights and beliefs about CAM, and evaluate their goals and expectations when using complementary and alternative medicine.

\section{Materials and Methods}

The study was carried out between 15 January 2018 and 28 March 2019 in 4 oncological centers in the southern region (Silesia) of Poland. A total of 864 hospitalized patients treated for malignant neoplasm took part in our study. The study was planned and carried out by final-year medical students studying oncology. The students worked under the supervision of oncologists and biostatisticians. A questionnaire was designed specifically for this study, in accordance with approved principles [13,14]. The questionnaire consisted of 24 main closed questions, with some questions allowing further options for respondents to complete when answering: 15 questions allowed the patient to select a single response, 7 questions allowed the patient to select 1 or more responses (as applicable to them) and 2 questions provided the patient with a scale of responses to select from (see Supplementary Files S1). Demographic data included age, gender, education, profession, working status, place of residence and some information about cancer diagnosis (tumor localization, date of diagnosis, stage of disease, intention of treatment). Patients were individually interviewed by students during the research survey for more reliable data collection. Students supported patients in reading and in their understanding of the questions and difficult phrases, encouraging them to give honest answers.

If patient had never heard about complementary and alternative medicine (CAM), they were excluded from further analysis. A total of 132 patients (15\%) of the 864 interviewed were excluded (117 patients were unaware of CAM and 15 patients were unable to provide a definitive response). Amongst the 732 patients who had indicated that they had knowledge of CAM, 342 patients $(46.7 \%)$ declared use of CAM. There were 10 patients $(1.4 \%)$ who were unable to provide a definitive response, and they were excluded from the comparative analysis. Of the 342 participants who used CAM, 237 patients $(69 \%)$ declared use of complementary medicine, 75 patients $(22 \%)$ declared use of complementary and alternative medicine, and 30 patients ( $9 \%$ ) declared use of alternative medicine (Figure 1). 


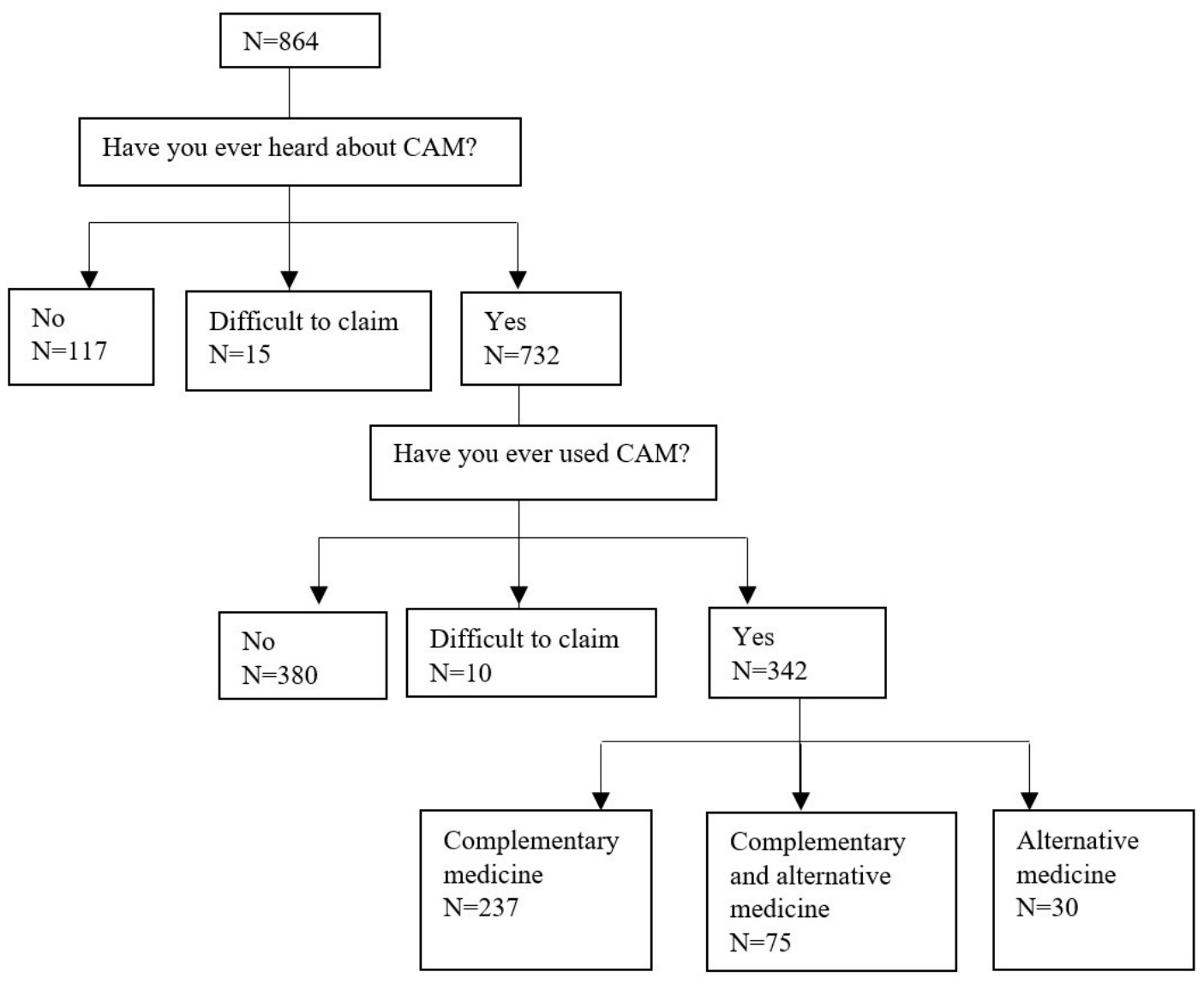

Figure 1. Flow diagram of patients included in the study.

The comprehensibility and acceptability of the questionnaire was validated by the physician (specialized in oncology) and the psycho-oncologist. A pilot study was conducted on a group of 20 patients, and the questionnaire was modified based on the results from the pilot. The reviewers verified that the questions were appropriately clear and unambiguous, based on answers from the first 20 patients. In a group of 38 patients, the reliability was then estimated. The validation procedure included a questionnaire that was carried out twice in a two-week interval on the same group of patients. An estimation of the degree of reproducibility of individual responses was made using Cohen's kappa coefficient of agreement. The repeatability was good (29\%) and very good $(71 \%)$, respectively.

The study protocol was presented to the Local Ethics Committee of the Medical University of Silesia in Katowice, Poland. The Local Ethics Committee decided that approval for this kind of study is not required. By agreeing to fill in the questionnaire, the patients gave their consent to participate in the study.

\section{Statistical Analysis}

Descriptive statistics were used (median, average, standard deviation, percentages). The chi-square test was used to compare the response prevalence between CAM users vs. non-users, associated with various factors. The age and time since diagnosis differences for each question were estimated using the Mann-Whitney test. The odds ratio (OR) with $95 \%$ confidence interval (CI) of using CAM was estimated in univariate and multivariate analysis using the logistic regression model. The variables with $p \leq 0.1$ in univariate analysis were included in multivariate model. A $p$ value $<0.05$ was considered to be significant. The analysis was conducted using Statistica (data analysis software system), version 13 (http:/ / statistica.io (accessed on 1 January 2018)) TIBCO Software Inc., Krakow, Poland (2017). 


\section{Results}

The study was carried out on a group of 864 cancer patients. A total of 732 patients, who had heard about CAM, were included to the analysis. Patients were in age range 18-93 years (median 62 years old). There were 407 women (55.6\%) and 325 men (44.4\%); $66.9 \%$ of patients had secondary- or higher-level education. More than half of patients were retired (58\%). Over $40 \%$ of respondents lived in cities of 50,000-200,000 inhabitants, $22 \%$ of respondents lived in big cities ( $>200,000$ inhabitants) and $15 \%$ of respondents resided in villages. The most frequent diagnosis for study participants was colon cancer $(23 \%)$, followed by upper digestive system cancer $(16 \%)$, lung cancer $(12 \%)$ and breast cancer $(12 \%)$. Half of patients were treated with the curative intent. A quarter of patients (26.5\%) were being treated for clinical stage IV disease (metastatic disease). The median time since cancer diagnosis was approximately 0.6 year (Table 1 ).

A total of 342 patients declared that they had used complementary and/or alternative medicine. Patients who were younger, highly educated and professionally active, with a longer period since diagnosis and at more advanced cancer stage had, statistically, more often used CAM. In the univariate analysis age, place of residence and stage of disease were significantly correlated with OR of CAM usage. In the multivariate model, the more advanced stage of cancer was noted as an independent factor increasing the probability of CAM usage in patients (Table 1 ).

Amongst 732 patients who had knowledge of CAM, 18\% had engaged in a conversation with a doctor about CAM. Most participants $(66 \%)$ had not experienced any health benefits of CAM; $18 \%$ of participants indicated that, in their opinion, CAM had harmful effects on health. Over a quarter of participants $(28.7 \%)$ claimed that CAM, used with cancer treatment, should be regulated by law.

The CAM treatments that were used the most by patients in this study were natural products $(43.6 \%)$, herbs $(32.5 \%)$, vitamin C (18.4\%) and other vitamins, dietary supplements and microelements (13.5\%). Some activities, such as special diets, bioenergy therapy, bioresonance therapy, hyperthermia or acupuncture, were used less frequently (1-3.5\%). Patients, who declared that they had used alternative medicine had mainly used high doses of vitamin C, amygdalin, herbs and marijuana (Figure 3 ).

Amongst 342 cancer patients who declared that they had used complementary and/or alternative medicine, the information they had about CAM was mostly obtained from the internet, friends, family and other patients (Figure 2).

Of the 342 patients who claimed that they had used CAM, 312 patients (91\%) had used it as a complementary medicine and 30 patients (9\%) undertook CAM as an alternative medicine. The use of complementary methods was mostly undertaken with the aim of strengthening the patient's immune system (70.8\%) and in the interest of improving morphological and biochemical test parameters $(63.5 \%)$ (Figure 4 ). More than half of patients who had used a complementary medicine (172 patients, $55 \%$ ) had noticed the positive effects of CAM therapy (Figure 5).

All patients, except 2, who stated that they were using CAM as an alternative therapy (28 patients) used it together with traditional cancer treatment. Only one patient claimed they were using alternative therapy instead of conventional therapy, and one patient used CAM after completion of their conventional treatment; additionally, $60 \%$ of patients did not inform their oncologist about their use of CAM. Half of the patients interviewed expected that CAM would increase the effectiveness of conventional cancer treatment, but positive effects of unconventional methods were only reported by $16.7 \%$ of patients in this group, and half of patients stopped using CAM. The most common reasons for discontinuation of CAM were no positive effects $(23.3 \%)$ and running out funds to continue the therapy $(16.7 \%) ; 30 \%$ of patients using CAM as an alternative method would not recommend it to other patients (Table 2). 
Table 1. Characteristics of patients and odds ratio (OR) of CAM usage due to various factors.

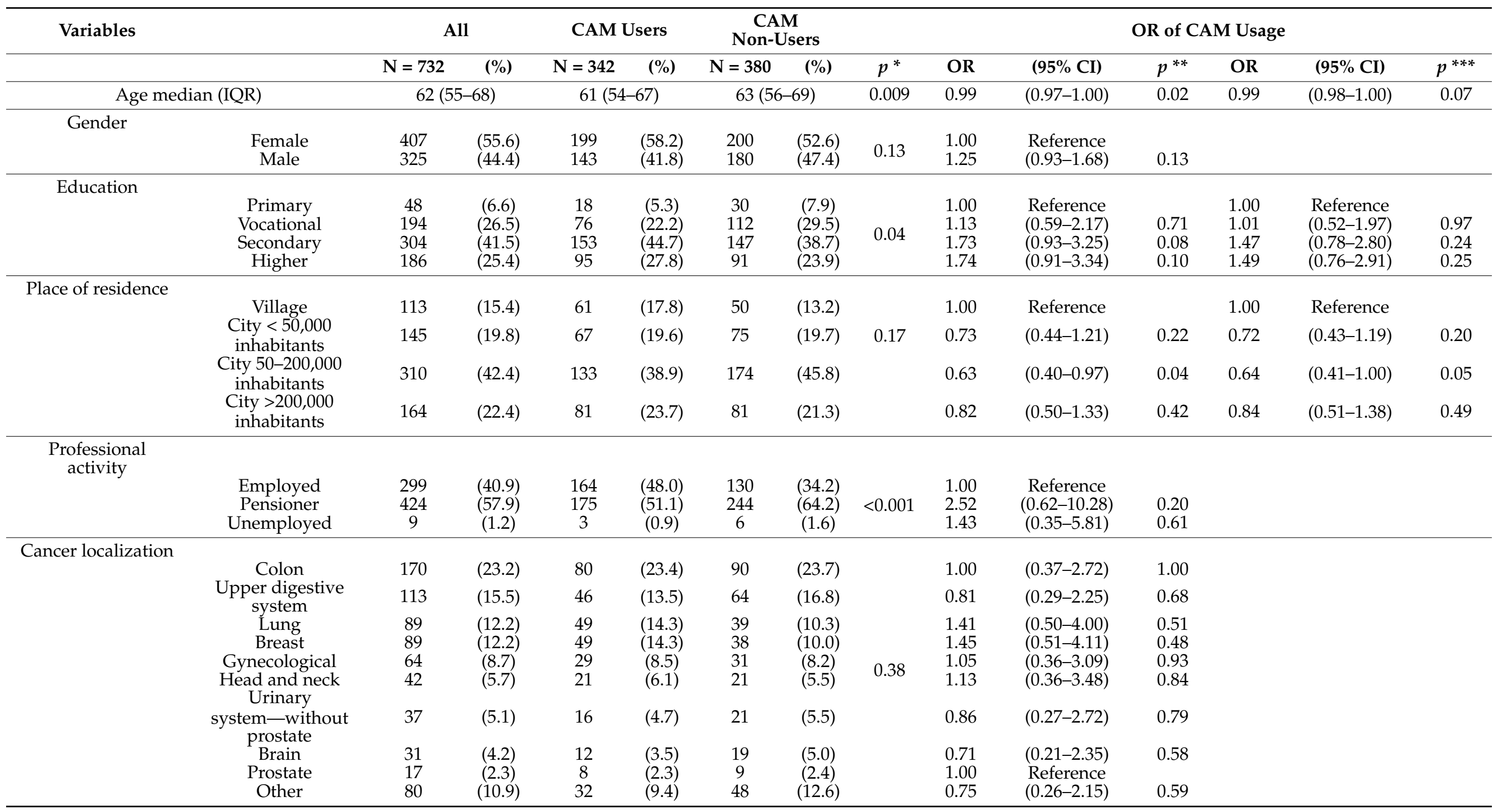


Table 1. Cont.

\begin{tabular}{|c|c|c|c|c|c|c|c|c|c|c|c|c|c|c|}
\hline \multirow{2}{*}{\multicolumn{2}{|c|}{ Variables }} & \multicolumn{2}{|c|}{ All } & \multicolumn{2}{|c|}{ CAM Users } & \multicolumn{2}{|c|}{$\begin{array}{c}\text { CAM } \\
\text { Non-Users } \\
\end{array}$} & \multirow[b]{2}{*}{$p^{*}$} & \multicolumn{6}{|c|}{ OR of CAM Usage } \\
\hline & & $\mathrm{N}=732$ & $(\%)$ & $\mathrm{N}=342$ & $(\%)$ & $\mathbf{N}=\mathbf{3 8 0}$ & $(\%)$ & & OR & $(95 \%$ CI $)$ & $p^{* *}$ & OR & $(95 \%$ CI $)$ & $p^{* * *}$ \\
\hline \multicolumn{2}{|c|}{ Time since diagnosis (years } & \multicolumn{2}{|c|}{$0.62(0.33-1.54)$} & \multicolumn{2}{|c|}{$0.70(0.41-1.71)$} & \multicolumn{2}{|c|}{$0.53(0.28-1.44)$} & 0.002 & 1.00 & $(0.99-1.00)$ & 0.13 & & & \\
\hline & Difficult to evaluate & 137 & $(18.7)$ & 59 & (17.3) & 76 & $(20.0)$ & & 1.26 & $(0.79-2.01)$ & 0.32 & 1.25 & $(0.78-2.01)$ & 0.35 \\
\hline
\end{tabular}

IQR-interquartile range; OR—odds ratio; CI—confidence interval * $p$-value estimated using chi-square test; ** $p$-value estimated using univariate logistic regression model; *** $p$-value estimated using multivariate logistic regression model. 


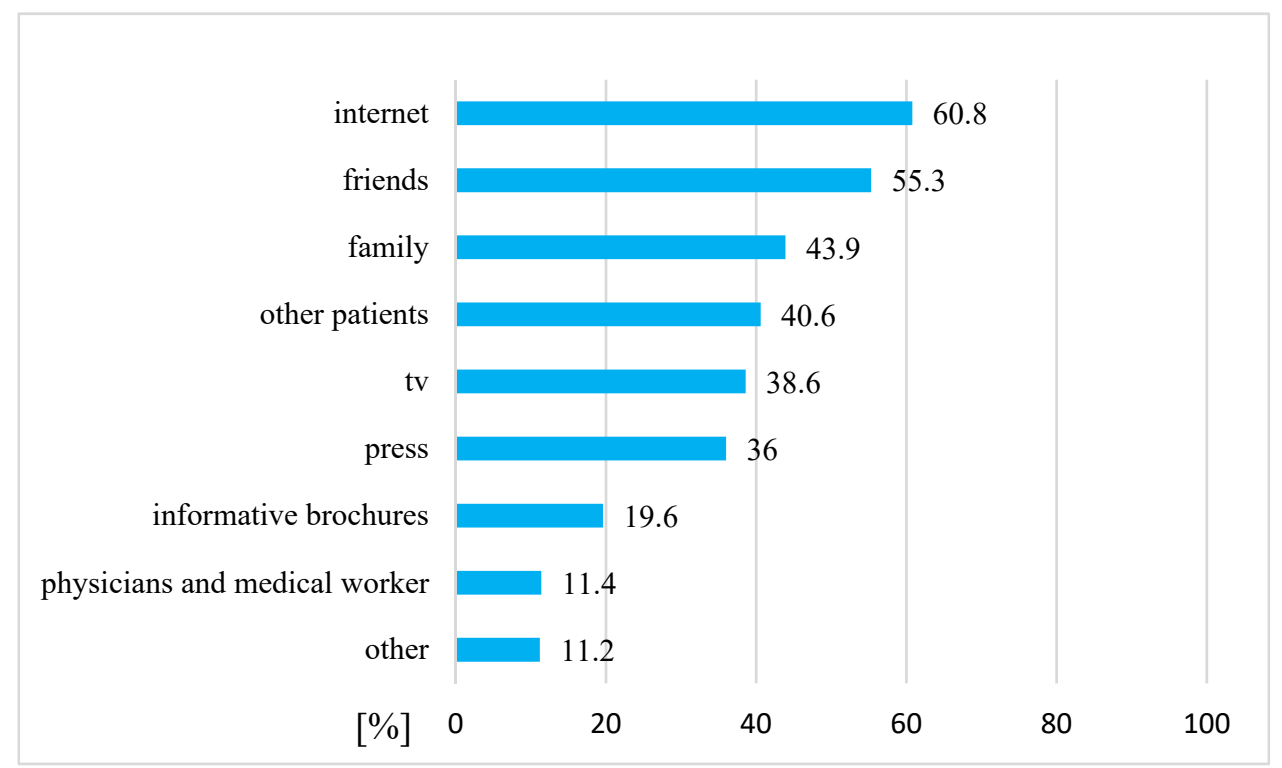

Figure 2. The sources of information about CAM amongst cancer patients who had used complementary and/or alternative medicine $(n=342)$.

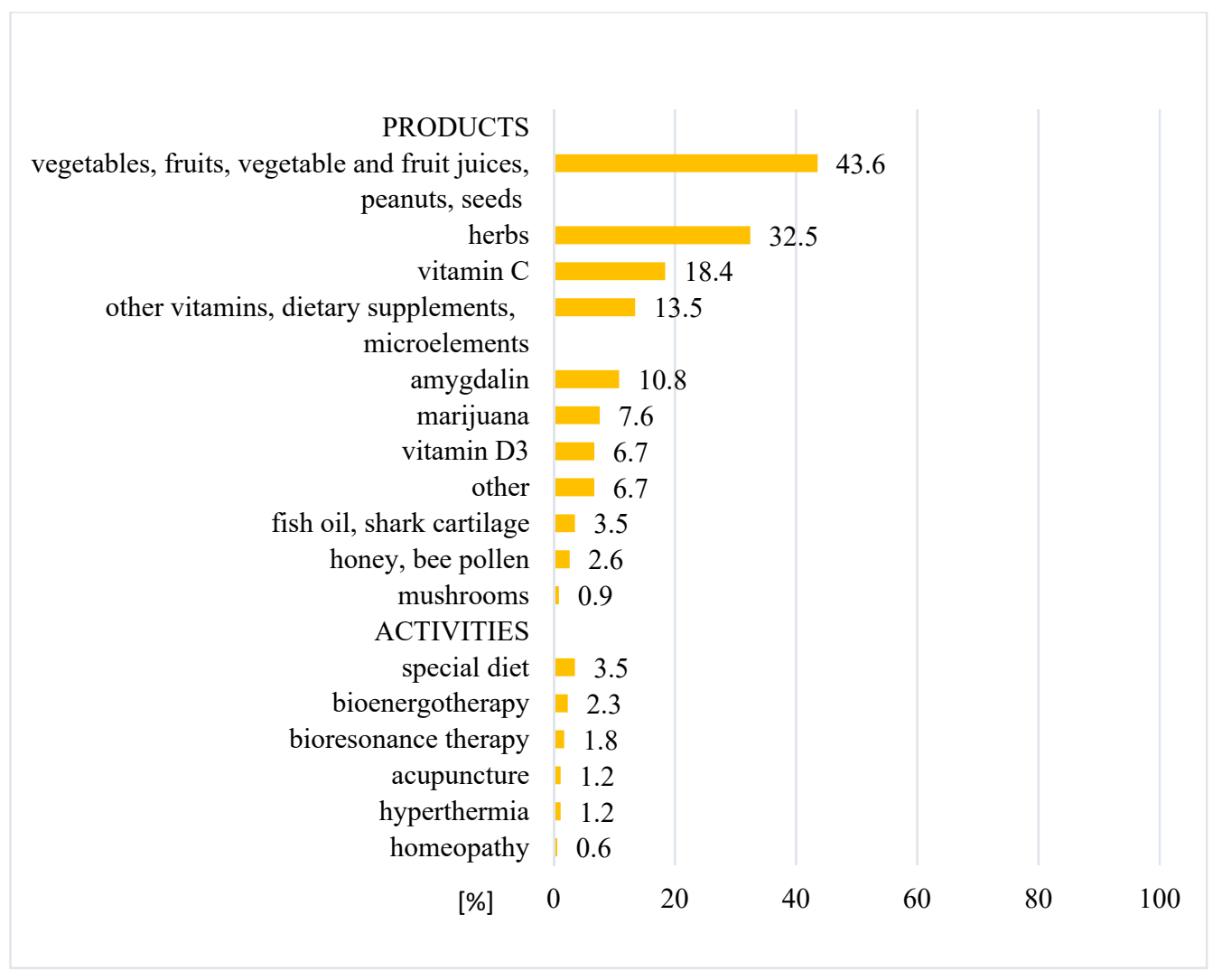

Figure 3. Distribution of used CAM modalities. 
To strengthen immunological system

To improve morphological and biochemical test parameters

To improve well-being

To reduce the side effects of conventional oncological therapy

To increase appetite / prevent weight loss

other

[\%] 0

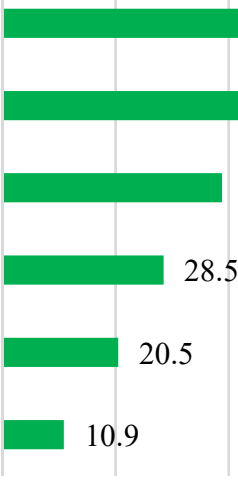

20

40

60

38.8

.5

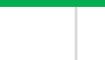

8

70.8

63.5

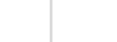

(1)

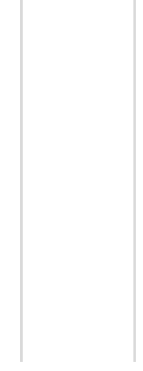

$80 \quad 100$

Figure 4. Reasons for CAM use as a complementary medicine $(n=312)$.

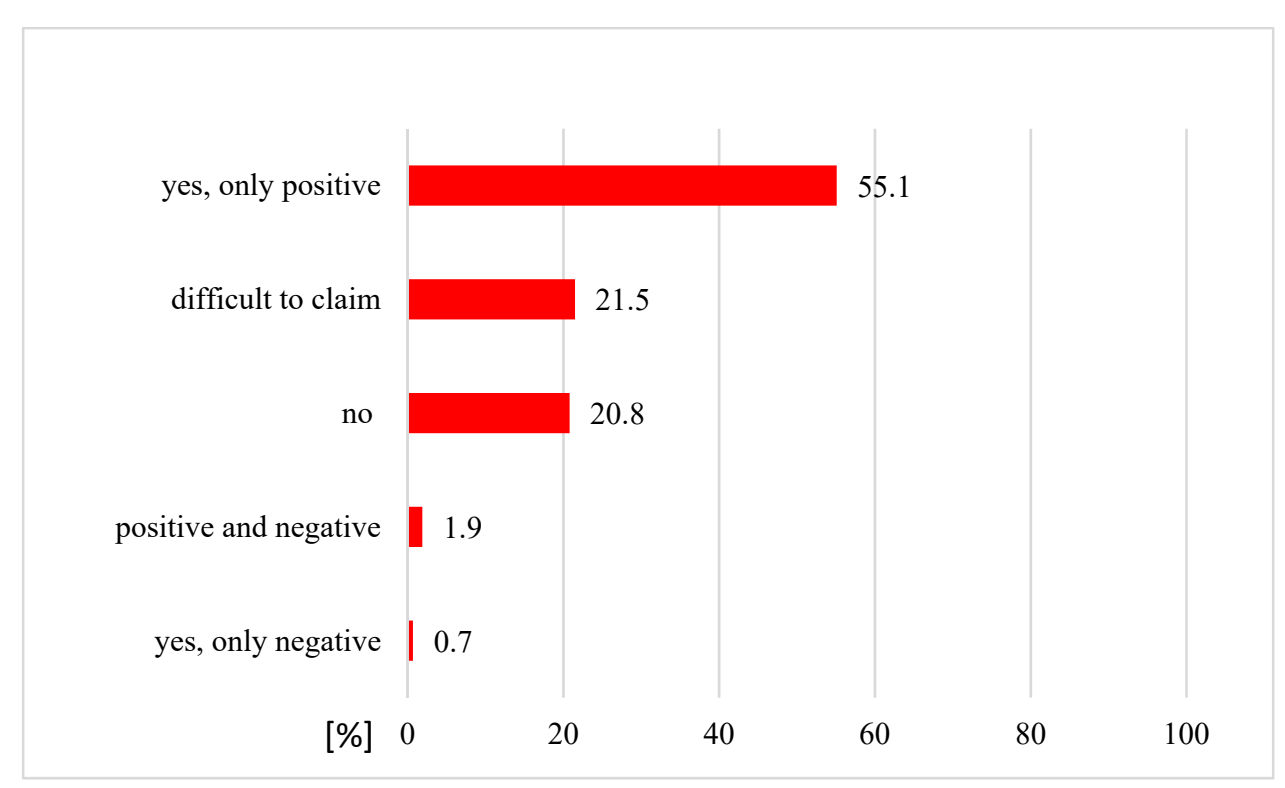

Figure 5. Perceived effects of CAM as a complementary medicine $(\mathrm{n}=312)$. 
Table 2. The answers of patients who declared that they had used CAM as an alternative medicine $(n=30)$.

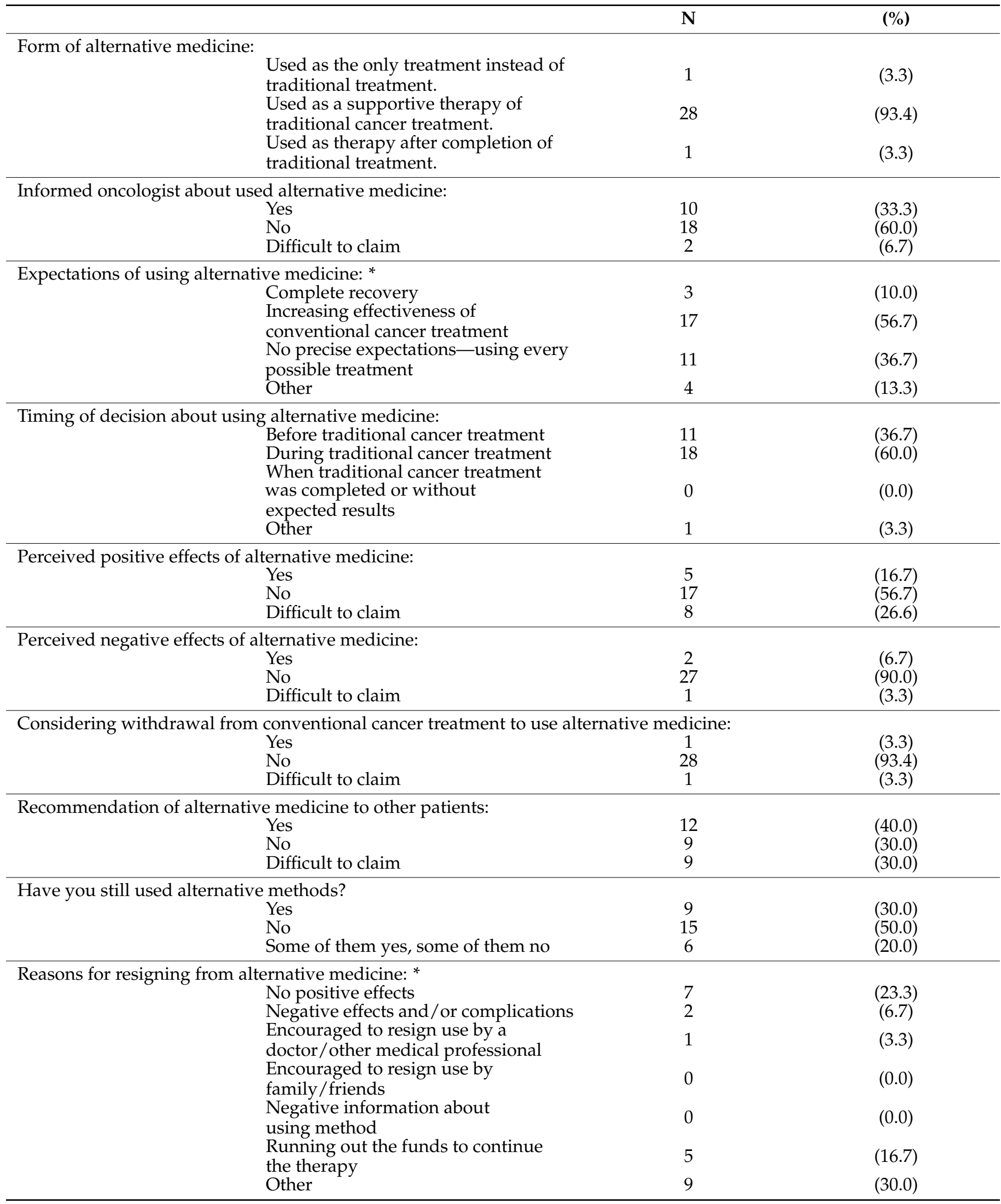




\section{Discussion}

\subsection{Prevalence and Reasons for CAM Use}

Cancer diagnosis is a very stressful situation. Oncological treatment takes a long time, causes a lot of side effects and decreases patients' quality of life. Some patients decided to use CAM because they wanted to decrease the side effects which they were experiencing from conventional therapy and wanted to improve their well-being. Other patients sought complementary and alternative methods of treatment with the hope that unconventional therapies would be more acceptable and comfortable for them. The overall prevalence of complementary and alternative medicine use by cancer patients is diverse between countries; $36 \%$ of cancer patients in European countries use CAM [15], and the percentage of cancer patients treated with CAM is $46 \%$ in Japan [16], 60\% in Canada [17], 70-83\% in the US [18,19], 85\% in Tunisia [20] and 98\% in Shanghai [21].

In our study, $13.5 \%$ of patients were not familiar with CAM. Half of patients (47\%) who had heard about CAM decided to use it; however, most of them (91\%) used CAM as a complementary therapy, rather than as the primary treatment for cancer. In Saudi Arabia, most patients (75\%) reported using CAM to treat cancer in [22]; additionally, $44.5 \%$ of Japanese patients using CAM claimed that they used complementary and alternative medicine to cure cancer [16]. Buckner et al. [17] reported that $51.6 \%$ of Canadian patients using CAM declared that they were "just trying to do everything that can help". Other reasons for CAM use included strengthening the immune system and in attempts to improving sleep and relaxation. In France, most patients indicated that their reason for using CAM was to prevent or treat the side effects of conventional therapy (81\%), and about half of patients reported that their reason was to improve their well-being [23]. Half of Italian cancer patients claimed that they used CAM, and of these, most of them thought that CAM could decrease the side effects of chemotherapy [24]. Another Polish study demonstrated that CAM is commonly used by patients following a primary diagnosis of cancer. Half of patients (49\%) hoped to enhance the effect of conventional therapy, whilst 16\% hoped to treat the side effects [25]. The main reasons that patients in our study used CAM were the following: strengthening the immune system (71\%), improvement of morphological and biochemical test parameters (64\%), improvement of well-being (39\%), and reducing the side effects of conventional therapy (29\%). Similar results were reported amongst cancer patients in Sweden [26].

In our study, only 1 patient out of 342 patients using CAM decided to resign completely from conventional treatment. In Saudi Arabia, where a large proportion of patients use CAM and believe that CAM could cure cancer, only about 3\% delayed beginning their conventional treatment in favor of CAM therapy [22]. In the analysis of Tascilar et al. [27], most patients from the countries studied used CAM together with conventional treatments.

\subsection{Predictors of CAM Usage}

In our study, patients of a younger age, who were highly educated and professionally active, with a longer period since diagnosis and at more advanced cancer stages, were more likely to use CAM. More advanced stage of disease was an independent factor for CAM use by cancer patients. Being female, of a younger age and highly educated predicted CAM use in other populations [16,20,22,24-31]. Additionally, CAM users were more likely to have advanced stages of cancer (IV) and have a history of delayed diagnosis [32]. CAM were more likely to be used by breast cancer and lung cancer patients [24]. In contrast, in our study, there were no significant differences among the prevalence of CAM usage based on cancer types.

\subsection{Types of CAM}

The types of CAM most frequently used by patients in our study were natural products, herbs, vitamin $C$ and other vitamins, dietary supplements and microelements. The same therapies have commonly been reported by other authors [17,24-26,28-33]; however, there are some therapy preferences that have been reported to be nation-specific. In the USA, the 
most popular CAM were vitamins, minerals, herbal supplements and green tea [28,29]. In Sweden, the most popular were vitamins, minerals and relaxation [26]. In Japan, patients often used mushrooms, propolis and Chinese herbs. In Saudi Arabia, some of the most commonly used CAM treatments were found to be Zamzam water, camel milk and olive oil [16,22]. People in Saudi Arabia also considered supplication and Quran recitation as part of CAM [22]. Americans often engaged in spiritual practices-meditation and prayer $[29,30]$.

\subsection{Sources of Information about CAM}

Patients often do not inform their doctors that they are using CAM; however, doctors do not ask their patients whether they are using additional therapies. In our study, only $18 \%$ of patients who were aware of CAM talked with their physicians about the possibility of using these methods in their treatment. Most of the patients $(60 \%)$ who reported using anti-cancer CAM did not inform their oncologist. Results from other studies confirmed that most of patients did not inform their oncologist about CAM [20,26]. Hyodo et al. [16] reported that over $60 \%$ of patients did not consult with a doctor over their usage of CAM. In France, only 33.5\% of cancer patients using CAM discussed it with oncologists [23]. However, in Italy, most CAM users informed their oncologists [24]. Patients declared that they did not talk about CAM with doctors for various reasons, including fear of disapproval, exclusion from clinical trials or simply because no health care professionals asked them [34,35]. In our study, patients mostly obtained information about complementary and alternative medicine from the internet, friends, family and other patients. In various other studies, the same sources of information on CAM were the most popular amongst cancer patients $[17,20,22,24,33,36]$. The Pew Internet Project for Health reported that more than $60 \%$ of people who used the internet were looking for health-related information, half of whom were looking for information on CAM [37]. Only about 6\% of Italian cancer patients had heard about CAM from a doctor [24]. Clinicians often do not ask patients about CAM use $[38,39]$. It could be a good idea to research whether doctors and other medical professionals (e.g., nurses) are interested in their patients' CAM use in future studies.

\subsection{Experiences and Recommendation of CAM Use}

Our study showed that more than half of patients (55\%) reported positive effects of complementary and alternative medicine. Amongst patients who used CAM as an anti-cancer therapy, only $16.7 \%$ reported positive effects (in their experience, CAM improved their mental health and well-being, physical condition, reduced the side effects of conventional therapy or had an anti-cancer effect). Half of patients using CAM as an anti-cancer therapy (50\%) discontinued using CAM because of no positive effects; $30 \%$ of patients using complementary and alternative medicine as an anti-cancer treatment would not recommend it to other patients. In Sweden, a few CAM users (5.6\%) reported adverse effects from CAM modalities [26]. Berretta et al. [24] demonstrated that beneficial effects of using CAM were reported by $34.5 \%$ of patients, whereas more than half of them (59\%) had no opinion about effects; however, $87.3 \%$ of respondents said they would recommend CAM, and 67.2\% trusted in CAM. In Japan, 24.3\% of cancer patients reported beneficial effects of CAM, such as pain relief, decreasing the side effects of conventional treatment, reducing tumor growth and improved well-being. About $70 \%$ of patients did not know whether CAM was effective [16]. Only a small percentage of patients using CAM reported side effects from the therapy $[16,24]$. In our study, $6.7 \%$ of patients using CAM as an alternative therapy reported negative effects, and only $2.6 \%$ of patients were using CAM as a complementary treatment. It is difficult to evaluate the adverse effects of overall CAM. Complementary and alternative medicine encompasses a diverse range of therapies and methods. Some CAM, such as acupuncture, meditation, massage and music therapy could be in some way beneficial for cancer patients and could improve their general health [40,41]. However, there are also known adverse interactions between CAM and some anti-cancer drugs (e.g., inhibition or activation of cytochromes) [24,27,42]. A significantly high adverse effect on survival was noted in cases of patients using CAM who delayed their conventional cancer treatment in favor of CAM; the 
five-year overall survival was significantly worse in cases of breast, lung and colorectal cancer patients [43]. Johnson et al. [44] showed that CAM use was associated with a significantly higher risk of death, because patients resigned from at least one standard oncological method of treatment. We noted that almost one in three of the patients surveyed in the present study believed that CAM should be regulated by law. CAM use by cancer patients is common. The Society of Integrative Oncology recommends integration of evidence-based CAM into regular oncologic care. Guidelines have been prepared based on reliable sources of information to help patients understand the risks and benefits of using CAM [45].

\subsection{Limitations}

Our study has some important limitations. One is the selection of a subpopulation of cancer patients who have been actively diagnosed or treated within oncological hospitals in stationary wards. Our study did not include patients who are not treated in a conventional way (for reasons such as refusal, very advanced disease, comorbidities, etc.) and we also did not include outpatients.

Our study was conducted across several hospitals in a large, highly urbanized and industrialized region; therefore, it may not be representative of the Polish population as a whole.

\section{Conclusions}

Almost half of the cancer patients surveyed in the present study reported using complementary and alternative medicine as a supportive therapy for strengthening their immune system, for improvement of morphological and biochemical test parameters, to reduce the side effects of conventional therapy and/or for the improvement of well-being. CAM use was most prevalent amongst patients of a younger age, who were highly educated and professionally active, with a longer period since diagnosis and at a more advanced cancer stage. Patients obtained information about CAM from the internet and through friends/family, rather than a doctor. Although a lot of cancer patients in Poland were found to use CAM, very few patients replaced or stopped their conventional treatment in favor of alternative medicine. Some alarming news about overuse and misuse of CAM therapies, reported in the popular press, were not confirmed by our study results. The contribution of our study to the health care service may be that Polish cancer patients need a little more education on CAM therapies-patients generally seek information about cancer treatment on the internet; therefore, there should be reliable services for patients, providing evidence-based CAM information.

In terms of cancer patients' needs, this study shows that a lot of patients used CAM, and seeking extra support was not unusual among patients. The main reasons for CAM use were improvement of blood parameters and quality of life, but most of patients (66\%) did not notice any positive effects of CAM. Of interest is that only $40 \%$ of patients who had used alternative medicines would recommend them to other patients.

It would be beneficial to encourage both patients and their doctors to talk about CAM (more than $80 \%$ of patients did not discuss it with their physician).

Supplementary Materials: The following supporting information can be downloaded at: https: / / www.mdpi.com/article/10.3390/ijerph19031600/s1, Files S1: The questionnaire (English version).

Author Contributions: Conceptualization, S.N., K.K., M.K. (Marta Kurzawa), M.K. (Malgorzata Kucharz), M.G., M.O., M.S., K.S.-B. and W.S.; methodology, K.K., M.K. (Marta Kurzawa), M.K. (Malgorzata Kucharz), M.G., M.O., M.S., K.S.-B., W.S., I.G., A.B.-N. and S.N.; validation, K.K, M.K. (Marta Kurzawa), M.K. (Malgorzata Kucharz), M.G., M.O., M.S., K.S.-B., W.S., K.O., M.R. and S.N.; formal analysis, K.O., M.R. and S.N.; investigation, K.K., M.K. (Marta Kurzawa), M.K. (Malgorzata Kucharz), M.G., M.O., M.S., K.S.-B., W.S., I.G. and A.B.-N.; data curation, K.O. and M.R.; writingoriginal draft preparation, K.O., M.R. and S.N.; writing-review and editing, K.K., M.K. (Marta Kurzawa), M.K. (Malgorzata Kucharz), M.G., M.O., M.S., K.S.-B., W.S., I.G. and A.B.-N.; visualization, M.R. and K.O.; project administration, K.K. and I.G.; All authors have read and agreed to the published version of the manuscript. 
Funding: This research received no external funding. The research was carried out as part of the activity of the Students Science Club.

\section{Institutional Review Board Statement: Not applicable.}

Informed Consent Statement: Informed consent was obtained from all subjects involved in the study.

Data Availability Statement: All data is available at the Department of Oncology and Radiotherapy, Medical University of Silesia in Katowice, Poland.

Conflicts of Interest: The authors declare no conflict of interest.

\section{References}

1. National Center for Complementary and Integrative Health. Available online: https://www.nccih.nih.gov/ (accessed on 1 January 2018).

2. Davis, E.L.; Oh, B.; Butow, P.N.; Mullan, B.A.; Clarke, S. Cancer patient disclosure and patient-doctor communication of complementary and alternative medicine use: A systematic review. Oncologist 2012, 17, 1475-1481. [CrossRef]

3. Horneber, M.; Bueschel, G.; Dennert, G.; Less, D.; Ritter, E.; Zwahlen, M. How many cancer patients use complementary and alternative medicine: A systematic review and metaanalysis. Integr. Cancer Ther. 2012, 11, 187-203. [CrossRef] [PubMed]

4. Angell, M.; Kassirer, J.P. Alternative medicine-the risks of untested and unregulated remedies. N. Engl. J. Med. 1998, 339, 839-841. [CrossRef] [PubMed]

5. Chang, E.Y.; Glissmeyer, M.; Tonnes, S.; Hudson, T.; Johnson, N. Outcomes of breast cancer in patients who use alternative therapies as primary treatment. Am. J. Surg. 2006, 192, 471-473. [CrossRef] [PubMed]

6. Coppes, M.J.; Anderson, R.A.; Egeler, R.M.; Wolff, J.E.A. Alternative therapies for the treatment of childhood cancer. N. Engl. J. Med. 1998, 339, 846-847. [CrossRef] [PubMed]

7. Ernst, E. Intangible risks of complementary and alternative medicine. J. Clin. Oncol. 2001, 19, 2365-2366. [CrossRef] [PubMed]

8. Han, E.; Johnson, N.; DelaMelena, T.; Glissmeyer, M.; Steinbocket, K. Alternative therapy used as primary treatment for breast cancer negatively impacts outcomes. Ann. Surg. Oncol. 2011, 18, 912-916. [CrossRef] [PubMed]

9. Joseph, K.; Vrouwe, S.; Kamruzzaman, A.; Balbaid, A.; Fenton, D.; Berendt, R.; Yu, A.; Tai, P. Outcome analysis of breast cancer patients who declined evidence-based treatment. World J. Surg. Oncol. 2012, 10, 118. [CrossRef]

10. Saquib, J.; Parker, B.A.; Natarajan, L.; Madlensky, L.; Saquib, N.; Patterson, R.E.; Newman, V.A.; Pierce, J.P. Prognosis following the use of complementary and alternative medicine in women diagnosed with breast cancer. Complement. Ther. Med. 2012, 20, 283-290. [CrossRef] [PubMed]

11. Aż 75 Proc. Pacjentów Onkologicznych Stosuje Jakieś Terapie Niekonwencjonalne. Available online: https://wyborcza.pl/ TylkoZdrowie/7,137474,21436975,az-75-proc-pacjentow-onkologicznych-stosuje-jakies-terapie.html (accessed on 3 March 2017).

12. Czy da Się Alternatywnie Wyleczyć Raka? Available online: https:/ /www.polityka.pl/tygodnikpolityka/nauka/1706436,1,czyda-sie-alternatywnie-wyleczyc-raka.read (accessed on 30 May 2017).

13. Burgess, T.F. A General Introduction to the Design of Questionnaires for Survey Research. In Guide to the Design of Questionnaires; University of Leeds: Leeds, UK, 2001.

14. Boparai, J.K.; Singh, S.; Kathuria, P. How to Design and Validate a Questionnaire: A Guide. Curr. Clin. Pharmacol. 2018, 13, 210-215. [CrossRef] [PubMed]

15. Molassiotis, A.; Fernádez-Ortega, P.; Pud, D.; Ozden, G.; Scott, J.A.; Panteli, V.; Margulies, A.; Browall, M.; Magri, M.; Selvekerova, S.; et al. Use of complementary and alternative medicine in cancer patients: A European survey. Ann. Oncol. 2005, 16, 655-663. [CrossRef] [PubMed]

16. Hyodo, I.; Amano, N.; Eguchi, K.; Narabayashi, M.; Imanishi, J.; Hirai, M.; Nakano, T.; Takashima, S. Nationwide survey on complementary and alternative medicine in cancer patients in Japan. J. Clin. Oncol. 2005, 23, 2645-2654. [CrossRef] [PubMed]

17. Buckner, C.A.; Lafrenie, R.M.; Dénommée, J.A.; Caswell, J.M.; Want, D.A. Complementary and alternative medicine use in patients before and after a cancer diagnosis. Curr. Oncol. 2018, 25, e275-e281. [CrossRef]

18. Richardson, M.A.; Sanders, T.; Palmer, J.L.; Greisinger, A.; Singletary, S.E. Complementary/alternative medicine use in a comprehensive cancer center and the implications for oncology. J. Clin. Oncol. 2000, 18, 2505-2514. [CrossRef]

19. Patterson, R.E.; Neuhouser, M.L.; Hedderson, M.M.; Schwartz, S.M.; Standish, L.J.; Bowen, D.J.; Marshall, L.M. Types of alternative medicine used by patients with breast, colon, or prostate cancer: Predictors, motives, and costs. J. Altern. Complement. Med. 2002, 8, 477-485. [CrossRef]

20. Labidi, S.; Ennouri, S.; Rachdi, H.; El Benna, H.; Mejri, N.; Daoud, N.; Berrazaga, Y.; Boussen, H. Use of complementary and alternative medicine in cancer: A Tunisian single-center experience. Bull. Cancer 2020, 107, 209-214. [CrossRef]

21. Cui, Y.; Shu, X.O.; Gao, Y.; Wen, W.; Ruan, Z.X.; Jin, F.; Zheng, W. Use of complementary and alternative medicine by Chinese women with breast cancer. Breast Cancer Res. Treat. 2004, 85, 263-270. [CrossRef] [PubMed]

22. Abuelgasim, K.A.; Alsharhan, Y.; Alenzi, T.; Alhazzani, A.; Ali, Y.Z.; Jazieh, A.R. The use of complementary and alternative medicine by patients with cancer: A cross-sectional survey in Saudi Arabia. BMC Complement. Altern. Med. 2018, 18, 88. [CrossRef] [PubMed] 
23. Gras, M.; Vallard, A.; Brosse, C.; Beneton, A.; Sotton, S.; Guyotat, D.; Fournel, P.; Daguenet, E.; Magné, N.; Morisson, S. Use of Complementary and Alternative Medicines among Cancer Patients: A Single-Center Study. Oncology 2019, 97, 18-25. [CrossRef]

24. Berretta, M.; Della Pepa, C.; Tralongo, P.; Fulvi, A.; Martellotta, F.; Lleshi, A.; Nasti, G.; Fisichella, R.; Romano, C.; De Divitiis, C.; et al. Use of complementary and alternative medicine (cam) in cancer patients: An Italian multicenter survey. Oncotarget 2017, 8, 24401-24414. [CrossRef] [PubMed]

25. Wojtacki, J.; Pawlowski, L.; Pawlowska, I.; Lichodziejewska-Niemierko, M. Complementary and alternative medicine (CAM) use among patients with cancer undergoing palliative care: A pilot study of a single institution in Poland. J. Clin. Oncol. 2017, 35, 178. [CrossRef]

26. Wode, K.; Henriksson, R.; Sharp, L.; Stoltenberg, A.; Hök Nordberg, J. Cancer patients' use of complementary and alternative medicine in Sweden: A cross-sectional study. BMC Complement. Altern. Med. 2019, 19, 62. [CrossRef]

27. Tascilar, M.; de Jong, F.A.; Verweij, J.; Mathijssen, R.H.J. Complementary and alternative medicine during cancer treatment: Beyond innocence. Oncologist 2006, 11, 732-741. [CrossRef] [PubMed]

28. Dy, G.K.; Bekele, L.; Hanson, L.J.; Furth, A.; Mandrekar, S.; Sloan, J.A.; Adjei, A.A. Complementary and alternative medicine use by patients enrolled onto phase I clinical trials. J. Clin. Oncol. 2004, 22, 4810-4815. [CrossRef]

29. Judson, P.L.; Abdallah, R.; Xiong, Y.; Ebbert, J.; Lancaster, J.M. Complementary and alternative medicine use in individuals presenting for care at a comprehensive cancer center. Integr. Cancer Ther. 2017, 16, 96-103. [CrossRef]

30. Gansler, T.; Kaw, C.; Crammer, C.; Smith, T. A population-based study of prevalence of complementary methods use by cancer survivors: A report from the American Cancer Society's studies of cancer survivors. Cancer 2008, 113, 1048-1057. [CrossRef] [PubMed]

31. Torres-Vega, D.; Cabanillas, F.; Rivera, N.; Sollivan, P.; Pardo, W.; Rivera, C.; Hernandez, M. Prevalence of complementary/alternative medicine use in cancer patients in a tertiary hospital in Puerto Rico. P. R. Health Sci. J. 2020, 39, 294-299. [PubMed]

32. Song, S.; Cohen, A.J.; Lui, H.; Mmonu, N.A.; Brody, H.; Patino, G.; Liaw, A.; Butler, C.; Fergus, K.B.; Mena, J.; et al. Use of GoFundMe ${ }^{\circledR}$ to crowdfund complementary and alternative medicine treatments for cancer. J. Cancer Res. Clin. Oncol. 2020, 146, 1857-1865. [CrossRef]

33. Michalczyk, K.; Pawlik, J.; Czekawy, I.; Kozłowski, M.; Cymbaluk-Płoska, A. Complementary methods in cancer treatment-Cure or curse? Int. J. Environ. Res. Public Health 2021, 18, 356. [CrossRef]

34. Ezeome, E.R.; Anarado, A.N. Use of complementary and alternative medicine by cancer patients at the University of Nigeria Teaching Hospital, Enugu, Nigeria. BMC Complement. Altern. Med. 2007, 7, 28. [CrossRef] [PubMed]

35. Quandt, S.A.; Chen, H.; Grzywacz, J.G.; Bell, R.A.; Lang, W.; Arcury, T.A. Use of complementary and alternative medicine by persons with arthritis: Results of the national health interview survey. Arthritis Rheum. 2005, 53, 748-755. [CrossRef] [PubMed]

36. Hamed Abdalla, M.E.A.; Ali, A.M.; Loong, L. The use of complementary and alternative medicine (CAM) among cancer patients at a tertiary hospital in Malaysia. Complement. Ther. Med. 2020, 50, 102343. [CrossRef] [PubMed]

37. Fox, S.; Rainie, L. Vital Decisions: How Internet Users Decide What Information to Trust When They or Their Loved Ones Are Sick; Pew Internet and American Life Project: Washington, DC, USA, 2002.

38. Shelley, B.M.; Sussman, A.L.; Williams, R.L.; Segal, A.R.; Crabtree, B.F.; Rios Net Clinicians. 'They don't ask me so I don't tell them': Patient-clinician communication about traditional, complementary, and alternative medicine. Ann. Fam. Med. 2009, 7, 139-147. [CrossRef] [PubMed]

39. Eisenberg, D.M.; Kessler, R.C.; Van Rompay, M.I.; Kaptchuk, T.J.; Wilkey, S.A.; Appel, S.; Davis, R.B. Perceptions about complementary therapies relative to conventional therapies among adults who use both: Results from a national survey. Ann. Intern. Med. 2001, 135, 344-351. [CrossRef] [PubMed]

40. Rosenthal, D.S.; Dean-Clower, E. Integrative medicine in hematology/oncology: Benefits, ethical considerations, and controversies. Hematol. Am. Soc. Hematol. Educ. Program 2005, 491-497. [CrossRef]

41. Mehling, W.E.; Jacobs, B.; Acree, M.; Wilson, L.; Bostrom, A.; West, J.; Acquah, J.; Burns, B.; Chapman, J.; Hecht, F.M. Symptom management with massage and acupuncture in postoperative cancer patients: A randomized controlled trial. J. Pain Symptom Manag. 2007, 33, 258-266. [CrossRef]

42. Brooks, S.L.; Rowan, G.; Michael, M. Potential issues with complementary medicines commonly used in the cancer population: A retrospective review of a tertiary cancer center's experience. Asia Pac. J. Clin. Oncol. 2018, 14, e535-e542. [CrossRef]

43. Johnson, S.B.; Park, H.S.; Gross, C.P.; Yu, J.B. Use of alternative medicine for cancer and its impact on survival. J. Natl. Cancer Inst. 2018, 110. [CrossRef]

44. Johnson, S.B.; Park, H.S.; Gross, C.P.; Yu, J.B. Complementary medicine, refusal of conventional cancer therapy, and survival among patients with curable cancers. JAMA Oncol. 2018, 4, 1375-1381. [CrossRef]

45. Deng, G.E.; Frenkel, M.; Cohen, L.; Cassileth, B.R.; Abrams, D.I.; Capodice, J.L.; Courneya, K.S.; Dryden, T.; Hanser, S.; Kumar, N.; et al. Evidence-based clinical practice guidelines for integrative oncology: Complementary therapies and botanicals. J. Soc. Integr. Oncol. 2009, 7, 85-120. [CrossRef] [PubMed] 